\title{
Research of Horizontal Tensile Strains Determined with Triaxial Appratus
}

\author{
Askar Zhussupbekov ${ }^{1}$, Balzhan Kaldanova ${ }^{2}$ \\ Eurasian National University, Astana, Kazakhstan \\ E-mails:'1astana-geostroi@mail.ru; ${ }^{2}$ balzhan_kaldanova@mail.ru (corresponding author)
}

\begin{abstract}
This report described the methodology and results of soil tests in the compression device with the ability to specify horizontal motions. The research introduced of behaviour of undermining soils - the areas affected by underground mining applications for the extraction of minerals, which resulted in the undermining thickness may occur uneven subsidence of the earth's surface and soil subsidence. This paper is important for understanding of interaction of foundations with subsidence ground.
\end{abstract}

Keywords: triaxial, tensile strain, compressibility factor, undermining work, horizontal deformations.

Conference topic: Design experiences and theoretical solutions.

\section{Introduction}

To study the actual deformability of soils under vertical load at occurrence of undermining work (Dalmatov et al. 2000) horizontal deformations developed a special compression device, the design of which is shown in Figure 1. Instead of fixed wall as a conventional compression device (Zhussupbekov, Fadeyev 1988) soil sample is placed in a rubber shell is crimped on the side surface water as in triaxial compression-type (Zaretsky et al. 1981).

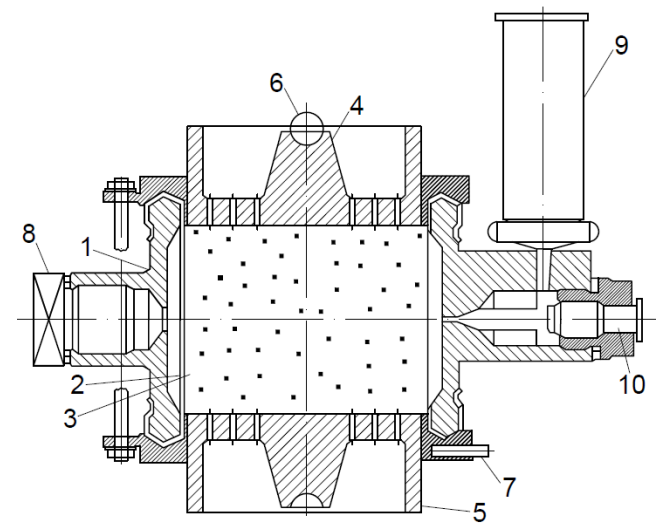

Fig. 1. A compression device with the ability to specify horizontal motions modeled true earth

1 - the case; 2 - camera; 3 - soil sample; 4,5 - the upper and lower pistons; 6 - a ball; 7 - locking screw; 8 - gauge; 9 - volumeter; 10 - controller

\section{The contents of new device}

The proposed compression device (Fig. 1) is formed as a cylindrical shell 1 , where installed camera 2 with the sample of soil 3. Camera 2 is made of a rubber thickness of $0.1-0.2 \mathrm{~mm}$, a cylinder the upper and lower parts of which are secured in the shell 1 . The camera 2 is provided with two pistons 4,5 , set to the opposite side of the sample 3 . The pistons 4,5 , are perforated. In the upper piston 4 a recess under a metallic ball 6 . Metallic ball 6 serves to supply the load centered on the loading device.

The lower plunger 5 is provided with a locking screw 7, which piston is fixed during the installation of the sample 3 into the chamber 2 . In the shell 1 have holes, one designed for a pressure measuring instrument 8 and the second 9 volumeter under the water filling the free space between the casing 1 and chamber 2 and the controller operation 10 horizontal tensile strains.

\section{The operations procedure of compression device}

The compression device operates as follows:

The soil sample 3 is placed into chamber 2 of cylindrical shell 1 which contains a liquid (water) under pressure; a pressure measuring instrument 8 is fixed.

At the time of mounting the sample 3 in the chamber 2 under the piston 5 is locked by the screw 7. To obtain the dependence between the stress and strain in the soil 3 vertical load is transmitted through the metallic ball 6 , which is located in the recess, with the locking screw 7 is removed.

Application of test soil sample two pistons in half reduces the amount of concentrated strain stretching a rubber diaphragm and accordingly increases twice the reliability of the device.

The test procedure is as follows: a sample placed in a compression device is held to the full consolidation under a given load of $0.3 \mathrm{MPa}$ (Kaldanova et al. 2015; Kaldanova, Zhussupbekov 2016).

According to the recommendations Medkov (Medkov 1979) step of loading the vertical load $\Delta \sigma_{1}$ taken within $0.05-0.1 \mathrm{MPa}$. 


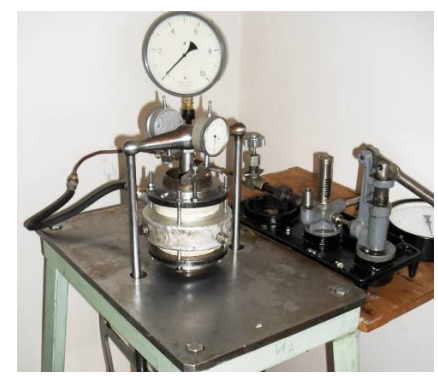

Fig. 2. The compression device at during time of testing

Each step of supporting up to stabilizes the vertical deformation. Under a given load the soil specimen is given in small steps up to the value of horizontal deformation $\varepsilon=12 \cdot 10^{-3}$ by issuing liquid from the shell of the device in the volumeter with the help of the regulator. The soil sample is held after each stage of the horizontal deformation until the extinction of the vertical deformation. The vertical deformation of soil samples was measured with a dial measuring instrument scale division $0.001 \mathrm{~mm}$.

The vertical load is transmitted through the lever a metallic ball disposed in the recess of the upper piston. The shoulder of lever is $10 \mathrm{~cm}$. Contact with the ground flat area of the stamp to reduce friction with silicone oil.
During the test, is plotted dependency graph lateral pressure $\sigma_{3}$; vertical deformation $\varepsilon_{1} ; \varepsilon_{v}$ - volumetric deformation depending of time $t$ for a predetermined vertical load and the horizontal defined by the corresponding deformation.

There were tested 18 of samples taken from a depth of $4 \mathrm{~m}$ of the walls 3 boreholes where then tested stamps (6 samples per borehole, Table 1).

\section{The test results of soil samples in the compression device}

The resulting test graphs are shown in Figures 3, 4 and 5. When specifying step deformities horizontal lateral pressure $\sigma_{3}$ value for the first time decreases, and time $t$ (Fig. 3) increases the time reference lateral deformation $\varepsilon_{3}$, and then over time, and further increases (Fig. 4). The first time point occurs loosening soil $\varepsilon_{v}$ (Fig. 5), further by a further increase in the magnitude of the vertical compressive strain of loosening is reduced.

According to the results of tests to determine the relative initial compressibility factor $\mathrm{m}_{v}{ }^{\text {start }}$, as the ratio of change in vertical deformation to change the vertical pressure by the formula (1), the vertical "apparent" compressibility factor $\mathrm{m}_{v}{ }^{\text {app}}$, as the ratio of change in vertical deformation taking into account the effect of the

Table 1. Physical and mechanical properties of soils experimental sites No. 1, No. 8, No. 12

\begin{tabular}{|c|c|c|c|c|c|c|c|c|c|c|}
\hline \multirow{3}{*}{$\begin{array}{l}\text { Number of } \\
\text { experimental } \\
\text { station }\end{array}$} & \multirow{3}{*}{$\begin{array}{l}\text { The } \\
\text { name } \\
\text { soil } \\
\text { base }\end{array}$} & \multirow{3}{*}{$\begin{array}{c}\text { The } \\
\text { depth of } \\
\text { soil } \\
\text { sampling, } \\
\text { m }\end{array}$} & \multirow{3}{*}{$\begin{array}{c}\text { Specific } \\
\text { density } \\
\gamma, \\
\mathrm{kN} / \mathrm{m}^{3}\end{array}$} & \multicolumn{3}{|c|}{$\begin{array}{l}\text { Water content weight in unit } \\
\text { fractions }\end{array}$} & \multirow{3}{*}{$\begin{array}{c}\text { Flow } \\
\text { rate } \\
\mathrm{I}_{\mathrm{L}}\end{array}$} & \multirow{3}{*}{$\begin{array}{l}\text { Compression } \\
\text { (odometer) } \\
\text { deformation } \\
\text { modulus } E \text {, } \\
\mathrm{MPa}\end{array}$} & \multirow{3}{*}{$\begin{array}{l}\text { Specific } \\
\text { cohesion } \\
c, \mathrm{kPa}\end{array}$} & \multirow{3}{*}{$\begin{array}{c}\text { Angle of } \\
\text { internal } \\
\text { friction } \varphi, \\
\text { degree }\end{array}$} \\
\hline & & & & \multirow{2}{*}{$\begin{array}{c}\text { The } \\
\text { natural } \\
\text { water } \\
\text { content, } \\
\%\end{array}$} & \multicolumn{2}{|c|}{ On the border } & & & & \\
\hline & & & & & $\begin{array}{c}\text { Flow } \\
\text { ability } \\
\left(\mathrm{W}_{1}\right)\end{array}$ & $\begin{array}{l}\text { Rolling } \\
\left(\mathrm{W}_{\mathrm{p}}\right)\end{array}$ & & & & \\
\hline \multirow{3}{*}{ No. 1} & \multirow{3}{*}{$\begin{array}{l}\text { Solid } \\
\text { gray } \\
\text { loam }\end{array}$} & 2.5 & 27.1 & 0.117 & 0.24 & 0.14 & $<0$ & 11.8 & 51 & 29 \\
\hline & & 4.0 & 27.2 & 0.119 & 0.25 & 0.16 & $<0$ & 18.2 & 62 & 26 \\
\hline & & 6.0 & 27.1 & 0.290 & 0.22 & 0.19 & $<0$ & 9.5 & 25 & 31 \\
\hline \multirow{3}{*}{ No. 8} & \multirow{3}{*}{$\begin{array}{l}\text { Solid } \\
\text { gray } \\
\text { loam }\end{array}$} & 2.5 & 27.0 & 0.33 & 0.33 & 0.20 & $<0$ & 11.8 & 24 & 29 \\
\hline & & 4.0 & 27.0 & 0.34 & 0.22 & 0.12 & $<0$ & 14.3 & 13 & 31 \\
\hline & & 6.0 & 27.0 & 0.33 & 0.21 & 0.12 & $<0$ & 11.1 & 50 & 26 \\
\hline \multirow{3}{*}{ No. 12} & \multirow{3}{*}{$\begin{array}{l}\text { Solid } \\
\text { gray } \\
\text { loam }\end{array}$} & 4.0 & 27.0 & 0.058 & 0.24 & 0.16 & $<0$ & 10.5 & 38 & 26 \\
\hline & & 6.0 & 27.1 & 0.128 & 0.27 & 0.20 & $<0$ & 11.8 & 51 & 26 \\
\hline & & 2.5 & 27.0 & 0.109 & 0.27 & 0.20 & $<0$ & & & \\
\hline \multicolumn{11}{|c|}{ (within the ground layer) } \\
\hline \multirow{3}{*}{ No. 1} & \multirow{3}{*}{$\begin{array}{l}\text { Solid } \\
\text { gray } \\
\text { loam }\end{array}$} & 2.5 & 27.1 & 0.117 & 0.24 & 0.14 & $<0$ & 11.8 & 49 & 29 \\
\hline & & 4.0 & 27.1 & 0.152 & 0.16 & 0.09 & $<0$ & 14.3 & 62 & 26 \\
\hline & & 6.0 & 27.1 & 0.22 & 0.19 & 0.03 & $<0$ & 9.5 & 22 & 30 \\
\hline \multirow{3}{*}{ No. 8} & \multirow{3}{*}{$\begin{array}{l}\text { Solid } \\
\text { gray } \\
\text { loam }\end{array}$} & 2.5 & 27.1 & 0.34 & 0.34 & 0.17 & $<0$ & 11.8 & 25 & 29 \\
\hline & & 4.0 & 27.1 & 0.34 & 0.34 & 0.22 & $<0$ & 14.0 & 13 & 27 \\
\hline & & 6.0 & 27.1 & 0.33 & 0.33 & 0.21 & $<0$ & 11.2 & 42 & 26 \\
\hline \multirow{3}{*}{ No. 12} & \multirow{3}{*}{$\begin{array}{l}\text { Solid } \\
\text { gray } \\
\text { loam }\end{array}$} & 2.5 & 27.0 & 0.059 & 0.22 & 0.15 & $<0$ & 11.5 & 35 & 26 \\
\hline & & 4.0 & 27.0 & 0.109 & 0.24 & 0.16 & $<0$ & 10.5 & 13 & 29 \\
\hline & & 6.0 & 27.0 & 0.128 & 0.27 & 0.20 & $<0$ & 11.5 & 50 & 22 \\
\hline
\end{tabular}




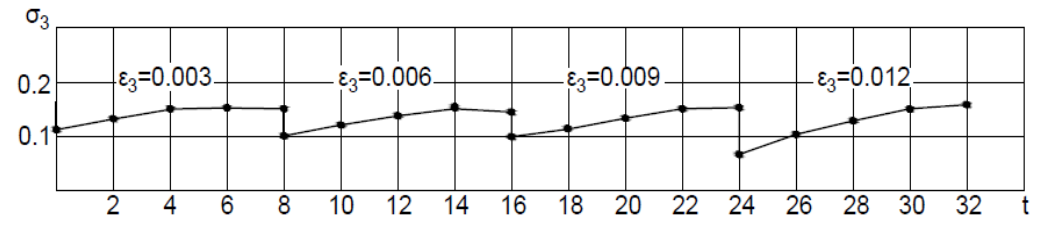

Fig. 3. Lateral pressure versus time

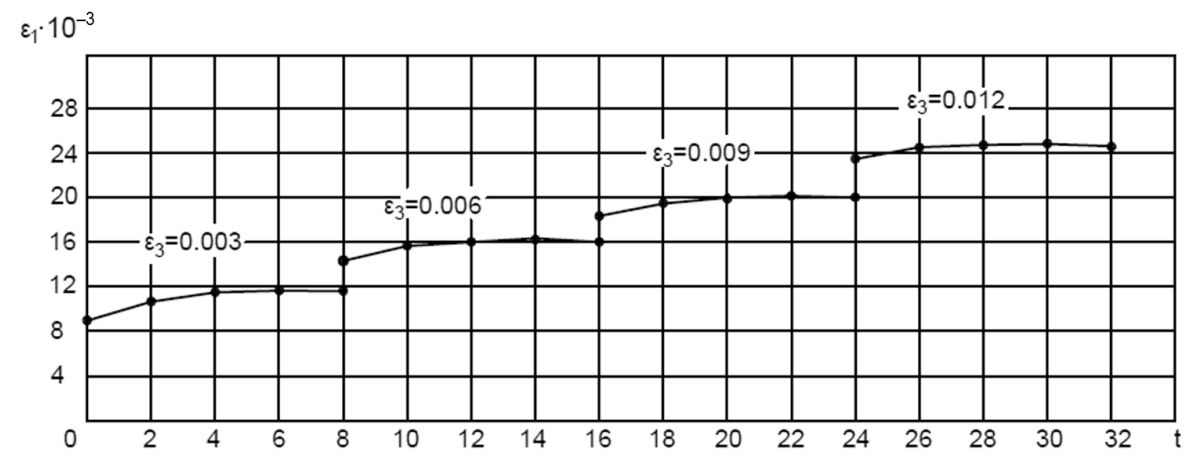

Fig. 4. Vertical deformation versus time

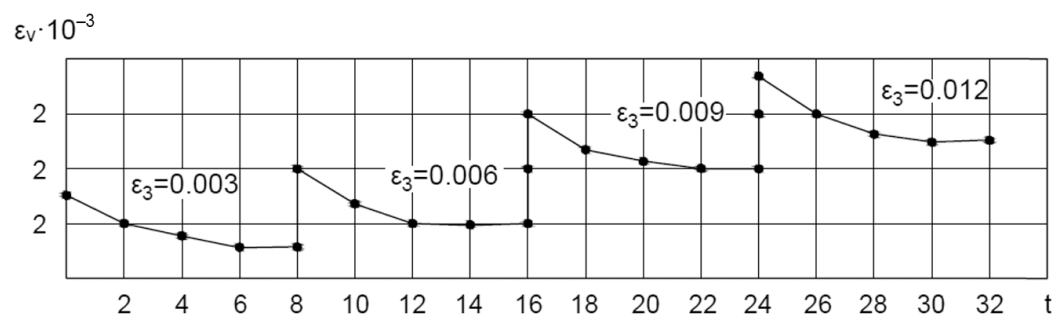

Fig. 5. Volume change of soil sample versus time

Table 2. Coefficient of compressibility of soil under vertical load at different horizontal tensile strain

\begin{tabular}{c|c|c|c|c}
\hline $\begin{array}{c}\text { Horizontal } \\
\text { tensile strain of the } \\
\text { soil sample } \\
\varepsilon \cdot 10^{-3}\end{array}$ & $\begin{array}{c}\text { Relative initial com- } \\
\text { pressibility factor, } \\
\mathrm{m}_{v}^{\text {start }} \\
\mathrm{MPa}^{-1}\end{array}$ & $\begin{array}{c}\text { "Apparent” compress- } \\
\text { ibility factor } \\
\mathrm{m}_{\mathrm{v}}^{\text {app }} \\
\mathrm{MPa}^{-1}\end{array}$ & $\begin{array}{c}\text { True initial coeffi- } \\
\text { cient of volume } \\
\text { compressibility } \\
\mathrm{m}_{\mathrm{u}}^{\text {start }} \\
\mathrm{MPa}^{-1}\end{array}$ & $\begin{array}{c}\text { True compressibility } \\
\text { factor taking into account } \\
\text { the effect of undermining } \\
\mathrm{m}_{\mathrm{u}}^{\text {under }} \\
\mathrm{MPa}^{-1}\end{array}$ \\
\hline 0 & 0.02 & - & 0.01 & - \\
3 & - & 0.037 & - & 0.0083 \\
6 & - & 0.053 & - & 0.004 \\
9 & - & 0.067 & - & 0.0033 \\
\hline
\end{tabular}

horizontal tensile strains to change the vertical pressure formula (2), the real initial and considering the influence factors undermining compressibility changes as the ratio of volumetric expansion medium pressure change by the formulas (3) and (4).

$$
\begin{aligned}
& \mathrm{m}_{v}{ }^{\text {start }}=\Delta \boldsymbol{\varepsilon}_{1} / \Delta \boldsymbol{\sigma}_{1} ; \\
& \mathrm{m}_{v}^{\text {app }}=\Delta \boldsymbol{\varepsilon}_{1}+\boldsymbol{\varepsilon}_{1}{ }^{\text {under }} / \Delta \boldsymbol{\sigma}_{1} ; \\
& \mathrm{m}_{\mathrm{u}}^{\text {start }}=\Delta \varepsilon_{1} / \Delta \sigma_{1}+2 \xi \Delta \sigma_{1}=\Delta \varepsilon_{1} / \Delta \sigma_{1}(1+2 \xi) ; \\
& \mathrm{m}_{\mathrm{u}}^{\text {under }}=\Delta \varepsilon_{1}+\varepsilon_{1}{ }^{\text {under }}-\varepsilon_{2}^{\text {under }} \varepsilon_{3}{ }^{\text {under }} / \Delta \sigma_{1}(1+2 \xi)= \\
& \Delta \varepsilon_{1}+\varepsilon_{1}^{\text {under }}-2 \varepsilon_{2}{ }^{\text {under }} / \Delta \sigma_{1}(1+2 \xi) .
\end{aligned}
$$

In the formulas (3), (4) - the pressure coefficient $\xi$ is defined as the ratio of the $\Delta \boldsymbol{\sigma}_{3} / \Delta \boldsymbol{\sigma}_{1}$. Test data (Table 2) shows that the "apparent" coefficient compressibility increasing when horizontal tensile strain $\mathrm{m}_{\mathrm{v}}{ }^{\text {app }}$ increases and the true coefficient of volume compressibility $\mathrm{m}_{\mathrm{u}}{ }^{\text {under }}$ under the influence of undermining decreases (Zhussupbekov, Aldungarova 2014; Zhussupbekov et al. 2015). This decrease is due to accumulating loosening of the sample (Figs 3,5). 


\section{Conclusions}

These laboratory tests allow studying the mechnism of deformation under the influence of udermining the bases by the horizontal tensile strain soil. Results show that the "apparent" coefficient compressibility increasing when horizontal tensile strain increases and the true coefficient of volume compressibility under the influence of undermining decreases. These investigations are important for designing of bearing capacity and settlements of foundations on udermining soil ground.

\section{References}

Dalmatov, B. I.; Bronin, V. N.; Karlov, V. D.; Mangushev, R. A. 2000. Soil mechanics. Part 1. Moscow. 204 p.

Kaldanova, B.; Hasegawa, A.; Kaneko, K. 2015. Comparison of mechanical properties of sand by using a triaxial compression device, The Journal of Hachinohe Institute of Technology 34: 117-122.
Kaldanova, B. O.; Zhussupbekov, A. Z. 2016. Mechanical properties of the soil basis by an equivalent material, The Journal of Kyrgyz State University of Construction, Transport and Architecture. N. Isanova 1(51).

Medkov, E. N. 1979. Practical guidelines to the study of the mechanical properties of soil with the applications stabilometric type. M-2. M.: Gosenergoizdat. 25 p.

Zhussupbekov, A. Z.; Tanaka, T.; Aldungarova, A. K. 2015. The effect of reinforcement on stability of model of the dam on undermining soil ground, in The $15^{\text {th }}$ Asian Regional Conference on Soil Mechanics and Geotechnical Engineering, 9-13 November 2015, Fukuoka, Japan.

Zhussupbekov, A. Z.; Aldungarova, A. K. 2014. The influence of the stress-strain state of the soil on the stability of the dam model, International Symposium on the Rheology of Soils, 8-11 October 2014, Kazan.

Zhussupbekov, A. Z.; Fadeyev, A. B. 1988. Triaxial compresion type. Kaz.NIITI, Kaz. Almaty.

Zaretsky, Y. K.; Vorontsov, E. I.; Malyshev, M. V.; Ramadan, I. H. 1981. Deformability and strength of sandy soil under plane strain conditions under different load path's, Bases, Foundations and Soil Mechanics 4: 25-28. 